\title{
The inheritance of sex ratio in the isopod, Sphaeroma rugicauda
}

\author{
D. J. Heath and \\ J. R. Ratford
}

Department of Biology, University of Essex, Colchester CO4 3SQ, U.K.

Sex ratio was examined in broods of Sphaeroma rugicauda females taken from a natural population. Some broods were male-dominated (arrhenogenic), some were female-dominated (thelygenic) while others were unbiased (amphogenic). There were no differences in mean brood size and no differences in mortality between broods with different sex ratios.

Laboratory crosses were set up between males and females derived from these three types of brood, in all nine combinations. The origin of the female proved to be the most important determinant of offspring sex ratio. Mothers from arrhenogenic broods produced arrhenogenic broods. Mothers from amphogenic and thelygenic broods produced broods of all types; most were amphogenic or thelygenic, but there were some arrhenogenic. There was some evidence of differences in mean brood size between broods with different sex ratios; larger than average sized broods had significantly more males than smaller than average broods. These results are consistent with those described in other species of isopod, where thelygeny is caused by a cytoplasmic feminising factor transmitted via females and arrhenogeny is due to a nuclear factor.

\section{INTRODUCTION}

The phenomenon of monogeny in isopods and amphipods, where some females produce maledominated broods, some produce female-dominated broods while others produce unbiased broods, presents an interesting and complicated situation (Bull, 1983). The terms arrhenogenic, thelygenic and amphogenic are used to describe both these three types of brood and also the parents who produce them (Bull, 1983). Thelygenic broods are caused by cytoplasmic sex factors in the amphipods Gammarus duebeni (Bulnheim, 1978) and Orchestia gammarella (Ginsburger-Vogel, 1975) and in the isopod Armadillidium vulgare (Juchault and Legrand, 1981). In all three cases the agent appears to be an interacellular micro-organism transmitted via the oocytes that causes immature animals to develop into females. The condition is therefore inherited maternally but may be subject to environmental modification by factors such as salinity and temperature. The underlying sex determination is not fully understood but it appears to be male heterogamety in $O$. gammarella and female heterogamety in $A$. vulgare. In $A$. vulgare some females are arrhenogenic, but the mode of inherit- ance of this condition is complex (Bull, 1983). The proportions of these three types of females vary in different populations of A. vulgare (Juchault and Legrand, 1981) but overall sex ratios are often biased towards females in this isopod and in both species of amphipod.

During breeding studies on colour and enzyme variants in the estuarine isopod Sphaeroma rugicauda it became apparent that it too exhibits monogeny with a similar range of females to that described in $A$. vulgare. The work described in this paper seeks to answer three questions relating to monogeny in $S$. rugicauda and of relevance to the studies already described.

1. What are the frequencies of the various types of female in a natural population? Previous estimates are often based on small sample sizes e.g., Juchault and Legrand (1981).

2. What pattern(s) of inheritance of sex ratio emerge when all possible combinations of matings are carried out, as would occur in a natural population?

3. Is there any evidence for differences in brood size (i.e., numbers of offspring) in broods with different sex ratios? Existing data on this point are confined to Gammarus; models for the joint 
evolution of cytoplasmic and nuclear sex factors usually assume equal fitnesses for different types of female (Bull, 1983).

\section{METHODS}

\section{(1) Sex ratio distribution in broods of females from the natural population}

There is one breeding season per year in $S$. rugicauda. Females are fertilised in early/mid May and release their offspring in $\mathrm{mid} /$ late June. Females were collected from the marsh at Alresford Creek, Essex (O.S. TM 082194) in May/June and kept at room temperature in individual petri dishes of seawater which was changed every 3-6 weeks. They were fed as required with green algae (Entermorpha sp.). Each female was checked every 2-3 days for the presence of offspring. Any offspring were removed immediately, counted and transferred to dishes of seawater as above, with a maximum of five animals per dish. Any dead offspring were recorded so that total brood size and mortality could be assessed. Offspring took $10-20$ weeks to reach the size $(>3.5 \mathrm{~mm})$ at which they could be sexed by examining the ventral surface (under a $\times 30$ dissecting microscope) for the presence of the paired penii characteristic of the male. Broods were then classified according to their sex ratio and the males and females isolated.

\section{(2) Classification of broods}

Broods were classified as female-biased, thelygenic (Th) or male-biased, arrhenogenic (Ar) if the sex ratio deviated significantly from $1: 1$ in the appropriate direction. If they did not deviate significantly from $1: 1$ they were classified as unbiased, amphogenic (Am). Amphogenic broods were further classified according to whether they exhibited an excess (non-significant) of females $(\mathrm{Am}+)$ or an excess of males $(\mathrm{Am}-)$ when it became apparent that these two categories were not equally represented. (Am) then denotes a brood with an exact 1:1 ratio. Any attempt to categorise broods in this way is bound to lead to misclassification, associated with type I and type II statistical errors. Some broods which display a significant excess of one sex may in fact be unbiased, while the reverse is also true. Smaller broods are more likely to be classified as amphogenic using this method, so this classification cannot be used as a basis for testing the differences in mean brood size between sex ratio categories. For this purpose broods were divided into four categories on the basis of the percentage of males present $(0-25,25 \cdot 1-50,50 \cdot 1$ $75,75 \cdot 1-100)$.

\section{(3) Laboratory studies on sex-ratio inheritance}

Males and females from broods of the three types were then paired in all nine possible combinations to investigate the inheritance of sex ratio. In each case the female parent is given first and the male second, where the symbols Ar, Am or Th refer to the type of brood from which the parent came. Thus in the cross $\mathrm{Ar} \times \mathrm{Ar}$ both female and male parents originated from male-dominated broods.

Culture and maintenance of these crosses were as described under (1) above, with the following additions. Crosses of different types were set up at the same time to minimise differences between them in terms of other factors. Females were kept isolated for at least two months before being used in a cross and the date of release of offspring was noted. Since most crosses produced offspring within 6-10 weeks of the cross being set up, this procedure served as an effective check that the female was unmated at the outset.

\section{RESULTS}

\section{Sex ratio distribution in broods from the natural population}

Fig. 1 shows the data for 185 broods, classified by per cent males in the brood. The distribution is polymodal and skewed towards low frequencies of males. There was a clear peak at 0-5 per cent males, corresponding to broods that were almost all female and a corresponding smaller peak of broods which were almost all male. There were strong suggestions of peaks at other points, e.g., 25-30 per cent males, 40-50 per cent males.

Table 1 shows the same data classified according to the criteria described in the preceding section. The most common type of brood was amphogenic (i.e., not significantly different from $1: 1)$. However, a significant majority of these $(69: 19)$ was female-biased $(\mathrm{Am}+)$. The next most common brood type was thelygenic followed by arrhenogenic. There were two broods (sex ratios $1: 3$ and $3: 2$ ) which were too small to be classified on this criterion. The overall sex ratio was 1486 males: 2837 females, giving a frequency of males of $0 \cdot 34$. 


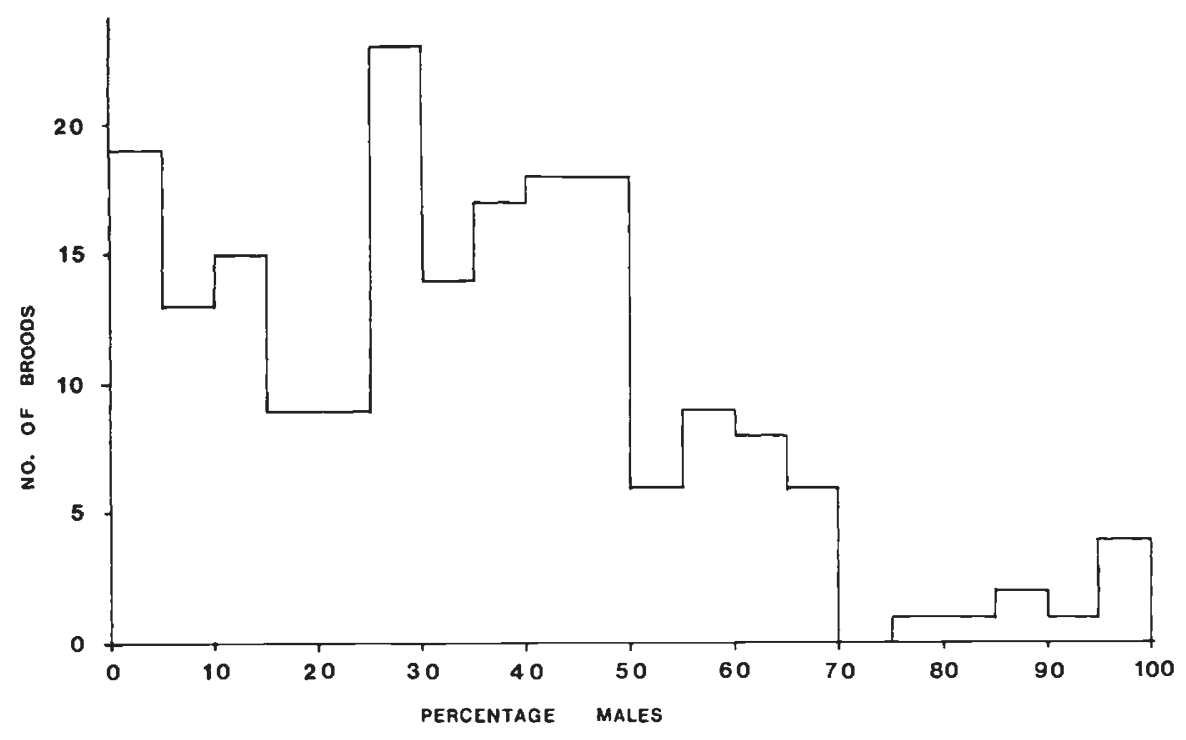

Figure 1 Sex ratio distribution in broods from the natural population.

Table 1 Brood type distribution in mortality and brood size in females from natural population

\begin{tabular}{|c|c|c|c|c|c|c|}
\hline Brood type & $\mathrm{n}$ & d & a & $\overrightarrow{\mathrm{b}}$ & n & $\%$ males \\
\hline Thelygenic & 74 & 270 & 1436 & $26 \cdot 25$ & 65 & $0-25 \cdot 0$ \\
\hline Amphogenic + & 69 & 454 & 2115 & $29 \cdot 53$ & 87 & $25 \cdot 1-50 \cdot 0$ \\
\hline Amphogenic & 8 & 108 & 545 & $27 \cdot 21$ & 24 & $50 \cdot 1-75$ \\
\hline Amphogenic- & 19 & & & & & \\
\hline Arrhenogenic & 13 & 36 & 227 & $29 \cdot 22$ & 9 & $75 \cdot 1-100$ \\
\hline Not classified & 2 & & & & & \\
\hline & 185 & & 4323 & & 185 & \\
\hline
\end{tabular}

$\mathrm{n}$, Number of broods; d, number of dead animals; a, number of live animals; $\bar{b}$, average brood size. Classification of broods by per cent male (see text) is given in the final column, other columns to the right of the vertical line refer only to this classification.

In order to examine the relationship between brood sex ratio, mortality and brood size the data in Fig. 1. were divided into the four sex ratio categories (per cent males; 0-25, 25.1-50, 50-1-75, $75 \cdot 1-100)$. The two small broods were included in the appropriate sex ratio categories. The proportions of animals dying in each of these categories (Table 1) were not significantly different $\left(\chi^{2}=4 \cdot 40\right.$, $3 \mathrm{df})$. Neither was there any significant difference in mean brood size (Table 1) between the different sex ratio categories when tested by analysis of variance $(F=0.5544, \mathrm{df} 3,181)$. However, if broods are divided into two size categories (smaller than average, larger than average) the overall frequency of males in large broods $(0.363)$ is significantly higher than that in small broods $(0 \cdot 323)$ $\left.\chi^{2}=6.7271 \mathrm{df}, P<0.01\right)$.

\section{Results of laboratory cross}

An initial inspection of the results where the distribution of brood types from different types of crosses is compared (table 2) suggests that the origin of the father was of little importance. Results are therefore grouped by the origin of the mother. In general, females from male-dominated broods tended to produce male-dominated broods, irrespective of the type of brood that provided the father. Females from unbiased broods or from female-dominated broods produced a wide range of brood types. Again there appeared to be little paternal influence. The brood distribution from amphogenic mothers does not differ markedly from that of thelygenic mothers, and in both cases brood types not found in either parent appear in 
Table 2 Distribution of brood types from laboratory crosses

\begin{tabular}{|c|c|c|c|c|c|c|}
\hline \multirow[b]{2}{*}{ Cross } & \multicolumn{6}{|c|}{ Brood type } \\
\hline & Th & $\mathrm{Am}+$ & Am & $\mathrm{Am}-$ & Ar & n.c. \\
\hline $\mathrm{Ar} \times \mathrm{Ar}$ & & & & & 3 & \\
\hline $\mathrm{Ar} \times \mathrm{Th}$ & & & & 1 & 2 & 1 \\
\hline $\mathrm{Ar} \times \mathrm{Am}$ & & & & 3 & 6 & 1 \\
\hline Total & & & & 4 & 11 & 2 \\
\hline
\end{tabular}

\begin{tabular}{lrrrrrr} 
Am $\times$ Ar & 8 & 8 & 2 & 3 & 1 & 1 \\
Am $\times$ Th & 2 & 6 & - & 2 & - & 3 \\
Am $\times$ Am & 5 & 10 & 1 & 1 & 2 & 6 \\
\hline Total & 15 & 24 & 3 & 6 & 3 & 10 \\
\hline Th $\times$ Ar & 6 & 5 & - & 5 & - & 3 \\
Th $\times$ Th & 2 & 4 & 1 & - & 2 & - \\
Th $\times$ Am & 8 & 17 & - & 7 & 5 & 8 \\
\hline Total & 16 & 26 & 1 & 12 & 7 & 11 \\
\hline
\end{tabular}

For details of crosses and brood classification see text. n.c., Not classified. Number of offspring in brood too small to allow brood to be classified, but data used in overall sex ratios in Table 3.

the progeny. For example, the cross of Am $\times$ Am produced both thelygenic and arrhenogenic broods and the cross $\mathrm{Th} \times \mathrm{Am}$ produced arrhenogenic broods. Table 3 gives a more detailed analysis of these results in terms of sex ratios, brood size, and brood mortality.

\section{Crosses involving Ar mothers}

Because many of the expected numbers would be small it is not valid to test the individual ratios for heterogeneity within each type of cross. If the data (within crosses) are pooled (table 3) it appears that crosses where the male was from a femaledominated or an unbiased brood produced more females than crosses where the male was from an Ar brood. The sex ratios from these three types of crosses are significantly heterogeneous (table 3 ) which shows that the origin of the male was not irrelevant.

\section{Crosses involving Am mothers}

The interpretation of these results is made more difficult by the possible misclassification of the brood-type of the parent. It has already been noted that extreme brood-types not present in either parent could occur in the progeny but it is possible that some of these may have arisen from misclassification. For example, two of the arrhenogenic broods had mothers who came from broods which, although classified as amphogenic, could easily have been arrhenogenic. The ratios were $(13: 6)$ and $(11: 5)$ respectively. The third arrhenogenic brood had a clear amphogenic mother (ratio 19:21) but a clear arrenogenic father. Most of the thelygenic broods had clear

Table 3 Sex ratios, mean brood size and mortality for laboratory crosses

\begin{tabular}{|c|c|c|c|c|c|c|c|}
\hline Cross type & No.? & No. $\sigma^{\star}$ & $\% \sigma^{2}$ & n & $\begin{array}{l}\chi^{2} \\
(2 \text { d.f. })\end{array}$ & $P$ & $\bar{b}$ \\
\hline $\mathrm{Ar} \times \mathrm{Ar}$ & 0 & 47 & 100 & 3 & & & $18 \cdot 67$ \\
\hline $\mathrm{Ar} \times \mathrm{Th}$ & 2 & 90 & $97 \cdot 8$ & 4 & $10 \cdot 94$ & $<0.01$ & $33 \cdot 25$ \\
\hline $\mathrm{Ar} \times \mathrm{Am}$ & 20 & 169 & $89 \cdot 4$ & 10 & & & $26 \cdot 40$ \\
\hline $\mathrm{Ar} \times \mathrm{Am}$ & 267 & 121 & $31 \cdot 2$ & 23 & & & $22 \cdot 22$ \\
\hline $\mathrm{Am} \times \mathrm{Th}$ & 89 & 40 & $31 \cdot 0$ & 13 & $\begin{array}{l}11 \cdot 79 \\
(1 \cdot 114)\end{array}$ & $\begin{array}{l}<0.01 \\
\mathrm{~ns}\end{array}$ & $14 \cdot 77$ \\
\hline $\mathrm{Am} \times \mathrm{Am}$ & $\begin{array}{c}248 \\
(239)\end{array}$ & $\begin{array}{c}179 \\
(126)\end{array}$ & $\begin{array}{c}41 \cdot 9 \\
(34 \cdot 5)\end{array}$ & 25 & & & $21 \cdot 48$ \\
\hline $\mathrm{Th} \times \mathrm{Ar}$ & $\begin{array}{c}238 \\
(135)\end{array}$ & $\begin{array}{c}89 \\
(117)\end{array}$ & $\begin{array}{c}27 \cdot 2 \\
(45 \cdot 3)\end{array}$ & 19 & & & $22 \cdot 26$ \\
\hline $\mathrm{Th} \times \mathrm{Th}$ & 124 & 96 & $43 \cdot 6$ & 9 & $\begin{array}{l}28.93 \\
(0.553)\end{array}$ & $\begin{array}{l}<0 \cdot 001 \\
\text { ns }\end{array}$ & $30 \cdot 44$ \\
\hline $\mathrm{Th} \times \mathrm{Am}$ & 479 & 375 & $43 \cdot 9$ & 45 & & & $24 \cdot 49$ \\
\hline$F$ & & & & & & & $1 \cdot 400$ \\
\hline df & & & & & & & 8,142 \\
\hline$P$ & & & & & & & ns \\
\hline
\end{tabular}

Cross type see text. No. $\$$, total number of females produced; No. $\delta$, total number of males produced; $\% \delta^{\circ}$, percentage males; $n$, number of crosses; $\chi^{2}=$ heterogeneity between cross types with 2 degrees of freedom; $\bar{b}$, mean brood size; F, variance ratio; df, degrees of freedom; $P$, probability; ns, not significant. 
amphogenic mothers but two broods had mothers who might have been thelygenics (ratios 6:13, $2: 8$ ). Two of the thelygenic broods had thelygenic fathers but the remainder had either arrhenogenic or amphogenic fathers. Some of the parental broods were small making misclassification a possibility, but there seems little doubt that some crosses had arrhenogenic fathers yet produced thelygenic broods as did one brood with an amphogenic father. In conclusion one can say, with a fair degree of confidence, that thelygenic broods can be produced even if neither parent comes from a thelygenic brood. One cannot make a similar statement for arrhenogenic broods.

The overall ratios for these three types of cross (table 3 ) are heterogeneous $\left(\chi^{2}=11 \cdot 79,2 \mathrm{df}\right)$ with Am $\times$ Am crosses producing more males than the other two categories. This is almost entirely due to one large arrhenogenic brood which had a possibly misclassified arrhenogenic mother. If this and the other possible misclassification are omitted the offspring sex ratio (given in parentheses in table 3 ) becomes $0 \cdot 345$. Ratios for the three types of cross are then homogeneous $\left(\chi^{2}=1 \cdot 114,2 \mathrm{df}\right)$.

\section{Crosses involving Th mothers}

Although these crosses produced progeny distributions with a strong bias towards female-dominated broods, there was a total of seven male-dominated broods, all of which originated from $\mathrm{Th} \times \mathrm{Th}$ or $\mathrm{Th} \times \mathrm{Am}$ crosses. Some of these could conceivably be misclassified broods or could have a misclassified parent. Others show clearly that maledominated broods can arise when neither parent came from such a brood.

The overall ratios for these three types of cross are heterogeneous (table 3 ), with $\mathrm{Th} \times \mathrm{Ar}$ crosses producing fewer males than the other two types. The $\mathrm{Th} \times$ Ar category is atypical because it includes the results of some 'pedigree' studies which showed thelygeny to be strongly inherited. If these pedigree results are omitted from the $\mathrm{Th} \times \mathrm{Ar}$ category (figures in parenthesis in table 3 ), it provides a more reasonable basis for a comparison with the other two categories. The overall sex ratios of the three types of crosses involving thelygenic mothers then become homogeneous $\left(\chi^{2}=0 \cdot 553\right)$, again implying no paternal effect.

Comparing the sex ratio in all broods of amphogenic mothers with that in broods of thelygenic mothers shows that mothers from femaledominated broods produced significantly more males than mothers from unbiased broods $(0 \cdot 423: 0 \cdot 323)$.

\section{Brood size and mortality in laboratory crosses}

There were no significant differences between mean brood sizes (table 3 ) produced in the nine different types of cross, when tested by ana'ysis of variance. The broods were then classified into four categories according to the percentage of males to provide a comparable situation to that for the broods of wild-caught females. Mean total brood sizes in the four categories were $18 \cdot 53,25 \cdot 80,24 \cdot 00$ and 26.32 (arranged in order of increasing frequency of males). These means were significantly different when tested by analysis of variance $(F=2 \cdot 788$, df $147,3, P=0 \cdot 042)$. Again the overall proportion of males $(0 \cdot 472)$ in broods of above average size was significantly greater than the proportion $(0.401)$ in broods of below average size $\left(\chi^{2}=11 \cdot 835, \mathrm{df}=1, P<0 \cdot 001\right)$.

The percentage of animals dying in each of the four sex ratio categories was as follows: $28 \cdot 9,22 \cdot 5$, $28 \cdot 7,24 \cdot 3$, giving rise to a significant difference, $\chi^{2}=15.68, \mathrm{df}=3, P<0 \cdot 01$.

\section{DISCUSSION}

The distribution of broad types in wild-caught females bears a marked resemblance to some of the distributions in Armadillidium vulgare described by Juchault and Legrand (1981). Although based on smaller sample sizes $(<80)$, females from populations from Caen and Niort showed polymodal distributions of brood sex ratios, with peaks in male frequencies at $0,<5$ and 100 per cent. Other populations they sampled showed evidence of similar patterns.

The proportions of the different types of females, however, did vary considerably. In the Niort population there were 34 thelygenics, 7 amphogenics and 39 arrhenogenics, while the figures for the Caen population were 18:9:3. Howard (1942) reported proportions of 9 thelygenic: 11 amphogenic in $A$. vulgare from Cambridge.

The overall sex ratio in $S$. rugicauda $(0 \cdot 34)$, with its strong bias towards females is again similar to results reported for $A$. vulgare. Samples from Niort, Celles, Caen and San Nicolao were homogeneous with respect to sex ratio (Juchault and Legrand, 1981), the average frequency of males being $0 \cdot 32$. Howard (1942) gives a value of 0.41 in $A$. vulgare, based on 19 samples. Heath and Khazaeli (1985) give much more extensive data on sex ratio in this population of S. rugicauda; three years' data confirm that males are at a frequency of 0.35 for most of the year. The broad 
similarity between these results suggests that there is some similarity in the underlying mechanism(s), leading to systems that are apparently stable at more or less the same point.

The analysis of brood size and brood mortality give conflicting results in wild females and laboratory crosses. In wild females there was no significant difference in mean brood size between the four categories, unlike the situation in laboratory crosses. One possible explanation is that other sources of brood size variability (e.g., female size, environmental conditions) were more diverse in wild females, thus obscuring differences in brood size associated with sex ratio. In both sets of data broods that were of above average size had a significantly higher proportion of males, which suggests that male-biased broods are larger. This would be consistent with a parasitic infection as the cause of female-biased sex ratios (see later), causing a metabolic drain on the host. However, Bulnheim (1975) reported no difference in a variety of life functions (including brood size) between infected and uninfected Gammarus duebeni and he concluded that the relationship between host and parasite was "rather well balanced". Even so one would expect that infection will always have some effect. Small differences, important to the dynamics of the system, will not be detected unless sample sizes are adequate. If there are fitness differences then models for the behaviour of these systems (Bull, 1983) will need to take them into account.

There was no significant difference in the proportion of animals dying in broods with different sex ratios of females taken from the field. This confirms the earlier suggestion of Howard (1942) that biased sex ratios are not the result of differential mortality of the sexes. The results from the laboratory crosses showed differences in mortality between broods with different sex ratios. There was no consistent pattern to this difference, i.e., female-dominated broods had a high mortality (28.9 per cent) but so too did broods with frequencies of males between $50 \cdot 1$ and 75 per cent. Broods with a slight excess of females had lower mortalities $(22 \cdot 5$ per cent $)$.

The breeding experiments gave apparently complex results, but they can be explained by a combination of cytoplasmic and nuclear factors affecting sex ratio, as has been proposed for other species. Unfortunately we have little direct evidence for these factors in S. rugicauda. The basic mechanism of sex determination in isopods may be male or female heterogamety (Bull, 1983), but cytological investigations of $S$. rugicauda
(Kieregyra, 1982) have not identified sex chromosomes unambiguously. According to Kieregyra (1982) the gonads of both sexes of $S$. rugicauda contain microscopic objects which resemble the feminising microsporidians in Gammarus described by Bulnheim (1975).

An infected female would pass the parasite, via the oocytes to her offspring. Males would be feminised, producing a female-biased (thelygenic) brood. Some offspring could, by chance, be uninfected, or the parasite could be killed or inactivated by adverse environmental conditions (Bulnheim, 1978). Such offspring would be subject to the normal sex determining mechanism and develop into either males or females, giving the posibility of broods with a varying excess of females. Some of these broods would be classified as amphogenic and could contain females of three types; uninfected, infected/parasite inactive, infected/parasite active. The last two types of females could, in turn, produce broods varying from amphogenic to thelygenic. This would explain the occurrence of thelygenic broods in crosses of $\mathrm{Am} \times \mathrm{Am}$.

Males could also be infected (presumably with an inactive feminising parasite) as described in Gammarus (Bulnheim, 1978). This would allow for the possibility of paternal transmission of thelygeny by one of two routes; (1) the direct transfer of the parasite to the female (and hence her brood) during copulation, (2) ingestion by the female of the parasite either from the medium or by cannibalism. This latter route has been experimentally verified in Gammarus (Bulnheim, 1975). The occurrence of two thelygenic broods in the cross $\mathrm{Am} \times \mathrm{Th}$ does not conclusively demonstrate paternal transmission because of the fact that amphogenic mothers may carry the parasite (see above), but male transmission of thelygeny has been indicated in A. vulgare (Bull, 1983).

The presence in the population of a cytoplasmic feminising factor would lead to an excess of females. This, in turn, would give an advantage to any inherited trait that led to the production of male-biased broods (Bull, 1983). The presence of arrhenogenic females in the population and the pattern of behaviour of this trait suggests a factor passed through females (crosses involving arrhenogenic mothers). The fact that crosses of $\mathrm{Ar} \times \mathrm{Ar}$ produce more males than the other two types of cross suggests that this factor can also be passed through males. The presence of arrhenogenic broods from crosses with amphogenic mothers is consistent with transmission through either sex if allowance is made for misclassification. 
The appearance of male-dominated broods in those crosses involving thelygenic mothers when the father is not arrhenogenic could have two explanations. The first involves assumptions about the interaction between feminising and masculinising factors when they occur together. If they "cancel out" then normal sex determination would proceed, leading to an amphogenic brood (as indeed occurs in some crosses of $\mathrm{Ar} \times \mathrm{Th}$ ). Subsequent loss of the parasite would lead to the expression of the masculinising factor alone in the next generation, accounting for the origin of maledominated broods in crosses of $\mathrm{Th} \times \mathrm{Am}$ (and $\mathrm{Am} \times \mathrm{Am})$. Alternatively they could arise because of the occurrence of animals which have the chromosome complement of one sex but the phenotype of the other. If, for example, the heterogametic sex (XY) is female, there will be some females in the population that are $\mathrm{XX}$ (because they are parasitised). If these lose the parasite they will produce nothing but males when they mate with an XX male. The same principle will operate if males are the heterogametic sex, except that then XY females that have lost the parasite would produce broods with either 75 per cent males or 66 per cent males (depending on the viability of YY individuals). This has been shown to be the explanation for the pattern of sex ratio inheritance in A. nasatum (Juchault and Legrand, 1979) and their results for laboratory crosses are rather similar to those described here. In $A$. nasatum arrhenogenic females produced either amphogenic or arrhenogenic broods, irrespective of the father. Amphogenic females produced broods of all three types as did thelygenic females.

In conclusion the results presented here raise many further questions on, for example, the nature of the loss of the feminising factor and the reasons for (and implications of) the differences in sex ratio between large and small broods. Inheritance of sex ratio in $S$. rugicauda is clearly a complex phenomenon, broadly compatible with that in Armadillidium.

\section{REFERENCES}

Bull, J. J. 1983. Evolution of Sex Determining Mechanisms. Benjamin/Cummings Publishing Company, Menlo Park BULNHEIM, H-P. 1975. Microsporidian infections of amphipods with special reference to host-parasite relationships: a review. Marine Fisheries Review, 37, 38-45.

BULNHEIM, H-P. 1978. Variability of the modes of sex determination in littoral amphipods. In Battaglia, B. and Beardmore, J. A. (eds) Marine Organisms: Genetics, Ecology and Evolution, Plenum Press, New York, pp. 529-548.

GINSBURGER-VOGEL, T. 1975. Temperature sensitive intersexuality and its determination in Orchestia gammarella Pallas. In Reinboth, R. (ed.) Intersexuality in the Animal Kingdom, Springer-Verlag, Berlin, pp. 106-120.

HEATH, D. J. AND KHAZAELI, A. A. $1985 . \quad$ Population dynamics of the estuarine isopod, Sphaeroma rugicauda. Estuarine Coastal and Shelf Science, 20, 105-116.

HOWARD, H. W. 1942. The genetics of Armadillidium vulgare Latr. II. Studies on the inheritance of monogeny and amphogeny. Journal of Genetics, 44, 143-159.

JUCHAULT, P. AND LEGRAND, J-J. 1979. Analyse génétique et physiologique de la détermination du sexe dans une population du Crustacé isopode oniscoide Armadillidium nasatum Budde-Lund. Archives de Zoologie Experimentale et Générale, 120, 25-43.

JUCHAULT, P. AND LEGRAND, J-J. 1981. Contribution à l'étude qualitative et quantitative des facteurs contrôlant le sexe dans les populations du crustacé isopode terrestre Armadillidium vulgare Latreille. II. Populations hébergeant le facteur féminisant $\mathrm{F}$ (Bacteroide intracytoplasmique). Archives de Zoologie Expérimentale et Générale, 122, 65-74.

KIEREGYRA, J. Z. 1982. Cytogenetics and Sex Determination in Sphaeroma rugicauda (Leach). Unpublished M.Sc. Thesis, University of Essex. 